\title{
COMP.BASILISK FAQ
}

\section{Frequently asked questions about basilisks.}

\section{David Langford}

\section{What is the purpose of this newsgroup?}

To provide a forum for discussion of basilisk (BLIT) images. Newsnet readers who prefer low traffic should read comp.basilisk.moderated, which carries only high-priority warnings and identifications of new forms.

\section{Can I post binary files here?}

If you are capable of asking this question you MUST immediately read news.announce.newusers, where regular postings warn that binary and especially image files may emphatically not be posted to any newsgroup. Many countries impose a mandatory death penalty for such action.

\section{Where does the acronym BLIT come from?}

The late unlamented Dr Vernon Berryman's system of maths-to-visual algorithms is known as the Berryman Logical Imaging Technique. This reflected the original paper's title: "On Thinkable Forms, with Notes towards a Logical Imaging Technique" (V. Berryman \& K. Turner, Nature 409, 340-342; 2001). Inevitably, the paper has since been suppressed and classified to a high level.

4. Is it true that science-fiction authors predicted basilisks?

Yes and no. The idea of unthinkable information that cracks the mind has a long SF pedigree, but no one got it quite right. William Gibson's Neuromancer (1984), the novel that popularized cyberspace, is often cited for its concept of 'black ice' software which strikes back at the minds of hackers - but this assumes direct neural connection to the net. Basilisks are far more deadly because they require no physical contact.

Much earlier, Fred Hoyle's The Black Cloud (1957) suggested that a download of knowledge provided by a would-be-helpful alien (who has superhuman mental capacity) could overload and burn out human minds.

A remarkable near-miss features in The Shapes of Sleep (1962) by J. B. Priestley, which imagines archetypal shapes that compulsively evoke particular emotions, intended for use in advertising.

Piers Anthony's Macroscope (1969) described the 'Destroyer sequence', a purposeful sequence of images used to safeguard the privacy of galactic communications by erasing the minds of eavesdroppers.

The comp.basilisk community does not want ever again to see another posting about the hoary coincidence that Macroscope appeared in the same year and month as the first episode of the British TV programme Monty Python's Flying Circus, with its famous sketch about the World's Funniest Joke that causes all hearers to laugh themselves to death.

\section{How does a basilisk operate?}

The short answer is: we mustn't say. Detailed information is classified beyond Top Secret.

The longer answer is based on a popularscience article by Berryman (New Scientist, 2001), which outlines his thinking. He imagined the human mind as a formal, deterministic computational system - a system that, as predicted by a variant of Gödel's Theorem in mathematics, can be crashed by thoughts that the mind is physically or logically incapable of thinking. The Logical Imaging Technique presents such a thought in purely visual form as a basilisk image which our optic nerves can't help but accept. The result is disastrous, like a software stealth-virus smuggled into the brain.

\section{Why 'basilisk'?}

It's the name of a mythical creature: a reptile whose mere gaze can turn people to stone. According to ancient myth, a basilisk can be safely viewed in a mirror. This is not generally true of the modern version although some highly asymmetric basilisks like B-756 are lethal only in unreflected or reflected form, depending on the dominant hemisphere of the victim's brain.

7. Is it just an urban legend that the first basilisk destroyed its creator?

Almost everything about the incident at the Cambridge IV supercomputer facility where Berryman conducted his last experiments has been suppressed and classified as highly undesirable knowledge. It's generally believed that Berryman and most of the facility staff died.

Subsequently, copies of basilisk B-1 leaked out. This image is famously known as the Parrot for its shape when blurred enough to allow safe viewing. B-1 remains the favourite choice of urban terrorists who use aerosols and stencils to spray basilisk images on walls by night.

But others were at work on Berryman's speculations. B-2 was soon generated at the Lawrence Livermore Laboratory and, disastrously, B-3 at MIT.

\section{Are there basilisks in the Mandelbrot set fractal?} Yes. There are two known families, at symmetrical positions, visible under extreme

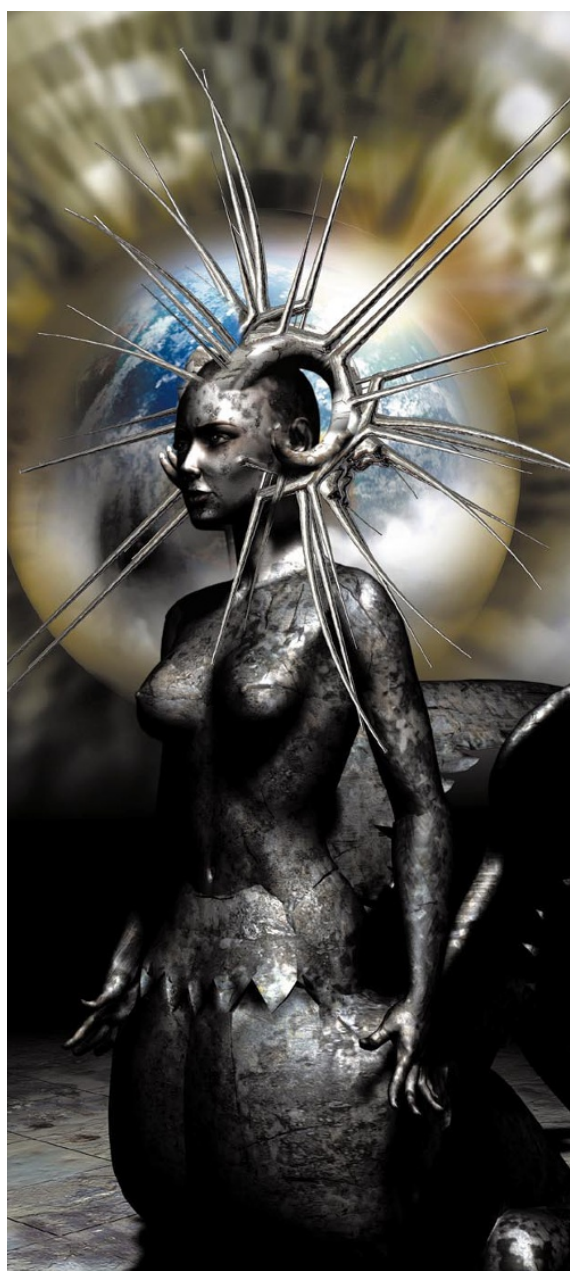

magnification. No, we're not telling you where.

9. How can I get permission to display images on my website?

This is a news.announce.newusers question, but keeps cropping up here. In brief: you can't, without a rarely granted government licence. Using anything other than plain ASCII text on websites or in e-mail is a guaranteed way of terminating your net account. We're all nostalgic about the old, colourful web, and about television, but today's risks are simply too great.

10. Is it true that Microsoft uses basilisk booby-traps to protect Windows 2005 from disassembly and pirating?

We could not possibly comment.

(Revised 27 June 2006)

David Langford, a former weapons physicist, has won many of science fiction's Hugo awards for criticism and commentary in the field. 